\title{
Processo sustentável de produção de carvão vegetal quanto aos aspectos: ambiental, econômico, social e cultural
}

\author{
Sueli de Fátima de Oliveira Miranda Santos ${ }^{a *}$, Kazuo Hatakeyama ${ }^{\mathrm{b}}$ \\ a*suelifom@hotmail.com, UTFPR, Brasil \\ bkhatakeyama@uol.com.br, Salvador, Brasil
}

\begin{abstract}
Resumo
O Brasil produz aproximadamente $1 / 3$ da produção mundial de carvão vegetal e sua quase totalidade é destinada à produção brasileira de ferro-gusa, ferro ligas e silício metálico. Quase $75 \%$ desse carvão ainda é produzido artesanalmente, utilizando-se principalmente a lenha de mata nativa. A pressão por sistemas produtivos sustentáveis tem dirigido a busca por tecnologias mais limpas e eficientes. A partir de pesquisa numa unidade industrial produtora de carvão vegetal pelo processo de carbonização em cilindros metálicos verticais, localizada no Paraná, este artigo objetiva mostrar que os aspectos de sustentabilidade deste processo estão no atendimento aos requisitos básicos de ser ecologicamente correto, economicamente viável, socialmente justo e culturalmente aceito. Este processo mostrou um potencial de economizar em torno de $25 \%$ de lenha, o atendimento à legislação trabalhista vigente e o atendimento aos anseios da sociedade, ao proporcionar aos trabalhadores condições dignas de trabalho e inserção social, quando comparado ao processo artesanal.
\end{abstract}

Palavras-chave

Produção de carvão vegetal. Carvão vegetal. Energia renovável.

\section{Introdução}

0 carvão vegetal é proveniente da queima parcial da madeira. Na era primitiva, o homem utilizava pedaços de madeira em chamas para iluminar as cavernas ou aquecer-se. Possivelmente não tardou a perceber que, ao utilizar a madeira queimada, de aspecto preto e friável, esta não produzia chama e nem tanta fumaça, gerando calor de forma mais controlável que aquele produzido pela queima direta da madeira (JUVILLAR, 1980), marcando a descoberta do carvão vegetal e seu uso como combustível.

0 fogo era utilizado para cocção de alimentos, como fonte de luz e de calor e evolutivamente para tratamento de materiais que serviriam para confecção de armas, ferramentas e utensílios, conferindo à lenha a qualificação de sistema energético mais antigo da humanidade.
À medida que a evolução da humanidade acontecia, a utilização do carvão vegetal foi se tornando mais intensa. Substituído por combustíveis fósseis em alguns casos, em muitos lares de países subdesenvolvidos ainda é um combustível imprescindível, seja por motivos econômicos ou financeiros (GUARDABASSI, 2006).

0 homem moderno procura aliar crescimento ao desenvolvimento sustentável desde a utilização da energia a vapor no século XVIII, fato marcante que abriu caminho para a consolidação do uso da energia em escala crescente para a modernidade, passando, nessa busca, pela utilização de fontes como o petróleo e a eletricidade, entre outras. A demanda pelo crescimento sustentável tem levado cada vez mais à necessidade da utilização de energias alternativas e renováveis. 
Porém, mesmo em alguns países onde o acesso a outras fontes energéticas é intenso, o carvão vegetal tem utilidade tecnológica importante, como no caso da produção de certos fundidos de ferro no Brasil que necessitam de matéria-prima (ferro-gusa) isenta de enxofre, sendo que este elemento químico está presente no carvão mineral.

Há que se salvaguardar a necessidade absoluta da utilização de florestas ser feita de forma racional, evitando a ocorrência de desastres ecológicos similares ao ocorrido na ilha de Madagascar, com suas florestas dizimadas pela exploração predatória.

A produção do carvão vegetal no Brasil responde por cerca de $1 / 3$ da produção mundial, aqui utilizada em sua quase totalidade para a siderurgia, mas produzida ainda, em sua grande maioria, como há um século, sem as preocupações básicas com a preservação do meio ambiente e com as condições de trabalho inadequadas (PINHEIRO et al., 2006).

Estas preocupações fazem parte das perspectivas do uso do Mecanismo de Desenvolvimento Limpo - MDL, do Protocolo de Kyoto. 0 MDL tem o propósito de aumentar a parcela de energia ecologicamente correta, produzida de maneira sustentável, incentivando a utilização de fontes renováveis e de diminuir a emissão de gases que causam o efeito estufa da atmosfera, contribuindo com o abrandamento deste efeito através do sequestro de carbono (BRASIL, 2005).

Por outro lado, os produtores de carvão vegetal, independentemente da escala de produção a que se dedicam, têm sentido os impactos no custo operacional devido às crescentes exigências de se utilizar a mão de obra e adquirir matéria-prima de forma legalizada, atendendo, ao mesmo tempo, aos apelos de uma produção mais limpa com baixos índices de poluição. A busca por alternativas que atendam a todos estes desígnios de forma econômica, leva à necessidade de processos mais eficientes.

Os dados foram coletados em duas unidades de produção, uma artesanal em fornos tipo "rabo quente" e outra industrial em fornos de cilindros metálicos verticais, ambas situadas no Estado do Paraná. Este artigo tem como objetivo analisar comparativamente os processos de carbonização e mostrar que os aspectos de sustentabilidade do processo industrial estão no atendimento aos requisitos básicos de ser ecologicamente correto, economicamente viável, socialmente justo e culturalmente aceito.

\section{0 uso do eucalipto na produção do carvão vegetal}

No Brasil, a atividade carvoeira tem tido como características: a devastação de florestas nativas, o uso de trabalho análogo à condição de escravo e a poluição do ar gerada pelos primitivos fornos de alvenaria, os quais emitem grandes quantidades de fumos, representando uma significativa fonte de poluição e contaminação ambiental.

Nos últimos 10 anos, o consumo de florestas plantadas em comparação ao consumo de florestas nativas para produção de carvão vegetal não evoluiu de maneira positiva do ponto de vista ambiental. Embora a área de florestas plantadas tenha crescido, não ocorreu na proporção do aumento da produção siderúrgica. Face ao acirramento nas questões ambientais, um planejamento neste sentido tem tomado corpo. Uma pequena reversão na tendência pode ser observada a partir de 2004.

0 eucalipto é uma das melhores opções para a produção de carvão vegetal, devido à rusticidade, produtividade e às características da madeira. Os reflorestamentos de eucalipto, planejados e manejados adequadamente, produzem árvores de troncos retos, uniformes e madeira com massa específica adequada para a obtenção de carvão de boa qualidade (PINHEIRO et al., 2006).

Em 2006, no Brasil, dos 5.373.417 ha de florestas plantadas com eucalipto e pinus, 66\% eram da espécie eucalipto, 4\% maior que em 2005. 0 Estado de Minas Gerais detém 31\% das florestas de eucalipto, São Paulo 23\% e a Bahia 23\% (ASSOCIAÇÃO..., 2007).

\section{Carbonização}

0 uso energético da biomassa vem sendo valorizado como forma alternativa ao uso de combustíveis fósseis, principalmente por ser uma fonte renovável.

$\mathrm{Na}$ conversão energética da biomassa (gramíneas, bagaço de cana, casca de arroz, casca de coco, madeira, entre outras), faz-se uso de processos termoquímicos. A biomassa é submetida à ação do calor até transformá-la em compostos mais simples (PINHEIRO et al., 2006).

A madeira é composta basicamente de carbono, oxigênio, água, hidrogênio, nitrogênio e sais minerais (OLIVEIRA et al., 1980), constituindo-se num dos componentes da biomassa de maior uso energético por possuir características atraentes tais como produtividade, qualidade e massa específica adequada, além do seu baixo custo (PINHEIRO et al., 2006).

Segundo Pinheiro et al. (2006), a carbonização é um processo em que a madeira é submetida a aquecimento entre 450 e $550{ }^{\circ} \mathrm{C} \mathrm{em}$ ambiente fechado, com pequena quantidade ou exclusão total de ar e durante o qual são liberados gases, vapores de água e líquidos orgânicos, permanecendo como resíduos, principalmente, o alcatrão e o carvão vegetal. 
Segundo Rezende (2006), o processo de carbonização do Eucalyptus ocorre em quatro fases:

- Fase 1 - Secagem: ocorre até $110^{\circ} \mathrm{C}$, quando apenas a umidade é liberada;

- Fase 11 - Torrefação: ocorre entre 110 e $250{ }^{\circ} \mathrm{C}$, sendo que, na temperatura de $180{ }^{\circ} \mathrm{C}$, tem início a liberação da água de constituição pela decomposição da celulose e hemicelulose. Pouco peso é perdido até $250^{\circ} \mathrm{C}$. Forma-se o tiço ou madeira torrada;

- Fase 111 - Carbonização: ocorre entre 250 e $350{ }^{\circ} \mathrm{C}$ e, com a intensificação da decomposição da celulose e hemicelulose, ocorre expressiva perda de peso, formando-se gás, óleo e água. Ao atingir a temperatura de $350{ }^{\circ} \mathrm{C}$, o carvão possui $75 \%$ de carbono fixo e se considera que a carbonização está praticamente pronta;

- Fase IV - Fixação: dos $350{ }^{\circ} \mathrm{C}$ em diante, ocorre redução gradual na liberação de elementos voláteis, principalmente gases combustiveis, continuando a fixação do carbono.

A carbonização é, então, a destilação da madeira que a transforma numa fração rica em carbono (o carvão vegetal) e noutra fração composta por vapores e gases (alcatrão, piro lenhosos e gases não condensáveis), de acordo com Sampaio et al. (2001). Essas frações são identificadas como os produtos oriundos da carbonização, conforme mostra a Tabela 1.

0 uso disseminado do carvão vegetal há gerações, por diversos setores, vem permitindo o aprimoramento dos processos de produção. Na tentativa de melhorar os métodos tradicionais de produção do carvão vegetal, os fornos metálicos vêm sendo aperfeiçoados visando o alcance de resultados em termos de redução do tempo de carbonização, aumento nos rendimentos volumétricos em estéreo de madeira/metro de carvão (st/MDC), aproveitamento dos subprodutos do processo, diminuição dos custos logísticos, diminuição na emissão de poluentes, entre tantos.

A evolução dos fornos para carbonização da matéria lenhosa no Brasil, depois dos fornos de terra, segue a sequência mostrada na Tabela 2 .

$\mathrm{Na}$ Europa, para atendimento às leis ambientais, tecnologias de carbonização com capacidade para produção em escala industrial, dotadas de mecanismos para recuperação dos subprodutos e de forma contínua foram substituindo as formas de produção altamente poluidoras.

Na realidade, estas tecnologias não foram criadas recentemente, dentre elas estão citados os processos em uso na Europa atualmente, como o ReichertLurgi (também conhecido como processo Degussa) e o Sific-Lambiotte (comercializado no Brasil como processo Carboprem), que foram criados em 1935 e 1947, respectivamente (PENEDO, 1982). Os altos custos de implantação e operação, aliados à pressão incipiente dos organismos ambientais da época podem ser as causas da demora em suas utilizações.

\section{Sustentabilidade}

Entende-se o termo sustentabilidade como algo que possua a qualidade de ser sustentável. Define-se sustentável como sendo algo capaz de se manter mais ou menos constante, ou estável, por longo período, segundo dicionário Aurélio. A ele estão atrelados termos como desenvolvimento ou crescimento econômico: sustentável.

Por crescimento econômico, entende-se todo e qualquer aumento na produção de bens e serviços, seja de um país ou de uma região, tendo como medida mais comum o aumento da renda per capita.

Para Almeida (2007), a concepção de desenvolvimento sustentável surgiu a partir da discussão internacional em torno do conceito de desenvolvimento, até então predominantemente atado à noção de crescimento.

Tabela 1. Produtos da carbonização.

\begin{tabular}{cc}
\hline Produtos da carbonização & $\%$ base seca \\
\hline Carvão (80\% Carbono fixo) & 33,0 \\
Ácido Pirolenhoso & 35,5 \\
(Ácido Acético) & $(5,0)$ \\
(Metanol) & $(2,0)$ \\
(Alcatrão Solúvel) & $(5,0)$ \\
(Água e outros) & $(23,5)$ \\
Alcatrão insolúvel & 6,5 \\
Gases Não Condensáveis (GNC) & 25,0 \\
(Hidrogênio - 0,63\%) & $(0,16)$ \\
(CO - 34\%) & $(8,5)$ \\
(CO - 62\%) & $(15,5)$ \\
(Metano - 2,43\%) & $(0,61)$ \\
(Etano - 0,13\%) & $(0,03)$ \\
(Outros - 0,81\%) & $(0,20)$ \\
\hline Total & 100,0
\end{tabular}

Tabela 2. Desempenho dos fornos de carbonização no Brasil.

\begin{tabular}{lcccc}
\hline Tipo de construção & $\begin{array}{c}\text { Ciclo de } \\
\text { operação } \\
\text { (horas) }\end{array}$ & $\begin{array}{c}\text { Lenha } \\
\text { (st) }\end{array}$ & $\begin{array}{c}\text { Carvão } \\
\text { (MDC) }\end{array}$ & $\begin{array}{c}\text { Rendimento } \\
\text { (st/MDC) }\end{array}$ \\
\hline \multicolumn{5}{c}{ Alvenaria com fonte interna de calor } \\
\hline Encosta ou barranco & 240 & 20 & 8,7 & 2,3 \\
"Rabo quente" & $144-168$ & 20 & 8,0 & 2,5 \\
Superfície JG ${ }^{\circledR}$ & 144 & $10-11$ & $4-5$ & 2,2 \\
Retangular V\&M & $264-312$ & $180-240$ & $95-130$ & 1,8 \\
Retangular ACESITA & 264 & 110 & 65 & 1,8 \\
\hline \multicolumn{5}{c}{ Metálicos com fonte interna de calor } \\
\hline JG semicontínuo & ND & ND & ND \\
\hline Metálicos com fonte externa de calor \\
\hline DPC semicontínuo & 72 & 80 & 53,3 \\
\hline Adaptado de Pinheiro et al. (2006); Lúcio (2006). & 1,50 \\
\hline \multicolumn{5}{c}{ ND } \\
\hline
\end{tabular}


A preocupação com a sustentabilidade vem tomando espaço cada vez maior nas decisões individuais, empresariais e governamentais, chamados por Almeida (2007) de atores do mundo tripolar - sociedade civil organizada, empresas e governos.

Esta tomada de espaço ocorre, entre outras, em função das advertências dos cientistas que representam o clamor vivo da sociedade e dos organismos internacionais para o crescente aquecimento global e suas possíveis consequências.

Esta preocupação com o equilíbrio entre aspectos econômicos, sociais e ambientais se tornou global mediante inúmeros fatos considerados importantes, tais como a fundação do Clube de Roma, em 1992; a criação do conceito ou base filosófica do desenvolvimento sustentável como sendo aquele que satisfaz as necessidades do presente sem comprometer a capacidade das gerações futuras satisfazerem as suas próprias necessidades, contido no documento Nosso Futuro Comum, em 1987 no Relatório Brundtland; em 1992, a ECO 92 no Rio de Janeiro; em 1997, o Protocolo de Kyoto que veio reforçar a Convenção sobre Mudanças Climáticas; em 1999, a Declaração do Milênio e a criação do Índice Dow Jones de Sustentabilidade, primeiro índice global criado para acompanhar o desempenho financeiro de empresas líderes em sustentabilidade com papéis na Bolsa de Valores de Nova York, o mesmo ocorrendo no Brasil com o Índice de Sustentabilidade Empresarial lançado pela BOVESPA em 2005.

Do ponto de vista do conceito, todo e qualquer empreendimento humano para ser sustentável necessariamente precisa ser economicamente viável, ecologicamente correto, socialmente justo e culturalmente aceito.

\section{Metodologia}

Os dados foram analisados com a finalidade de identificar a viabilidade econômica, os impactos ambientais, sociais e culturais da produção de carvão vegetal pelo processo de carbonização em cilindros metálicos verticais em comparação com o processo de carbonização em fornos de alvenaria tipo "rabo quente".

0 processo de carbonização em fornos de alvenaria tipo "rabo quente" faz parte do Processo Artesanal de produção do carvão vegetal e, segundo Pinheiro et al. (2006) é responsável por cerca de 70\% do carvão produzido no Brasil.

Os fornos do tipo "rabo quente" realizam um ciclo a cada seis ou sete dias, podendo chegar a dez dias se a umidade da lenha for elevada, cujo período se divide em duas partes. Primeiro vem o acendimento do forno e o controle da entrada de ar, quando ocorre efetivamente a carbonização. Terminada a carbonização, que dura em média três dias, o forno é completamente vedado com argila e deixado em resfriamento até atingir temperaturas internas em torno de 40 a $50{ }^{\circ} \mathrm{C}$, quando então é possível a descarga do forno sem risco de ignição do carvão ao entrar em contato com o ar (COLOMBO; PIMENTA; HATAKEYAMA, 2006).

Em função do custo de construção e da facilidade de operação é comum encontrar carvoarias com até 120 fornos, construídos junto às florestas nativas ou cultivadas, conforme exemplo mostrado na Figura 1.

0 processo de carbonização em cilindros metálicos verticais (PCCMV) faz parte do processo industrial de produção do carvão vegetal, em função das características de volume, nível de investimento, possibilidade de organização do trabalho, entre outras.

Os dados referentes a este processo foram coletados numa unidade de produção de carvão vegetal (UPC) localizada no Estado do Paraná e que utiliza o processo de carbonização em cilindros metálicos verticais. Possui como característica principal a produção em escala industrial, à qual se agregam os aspectos técnicos, econômicos, ambientais e sociais como fatores diferenciais entre os processos utilizados atualmente, conforme mostra a Figura 2.
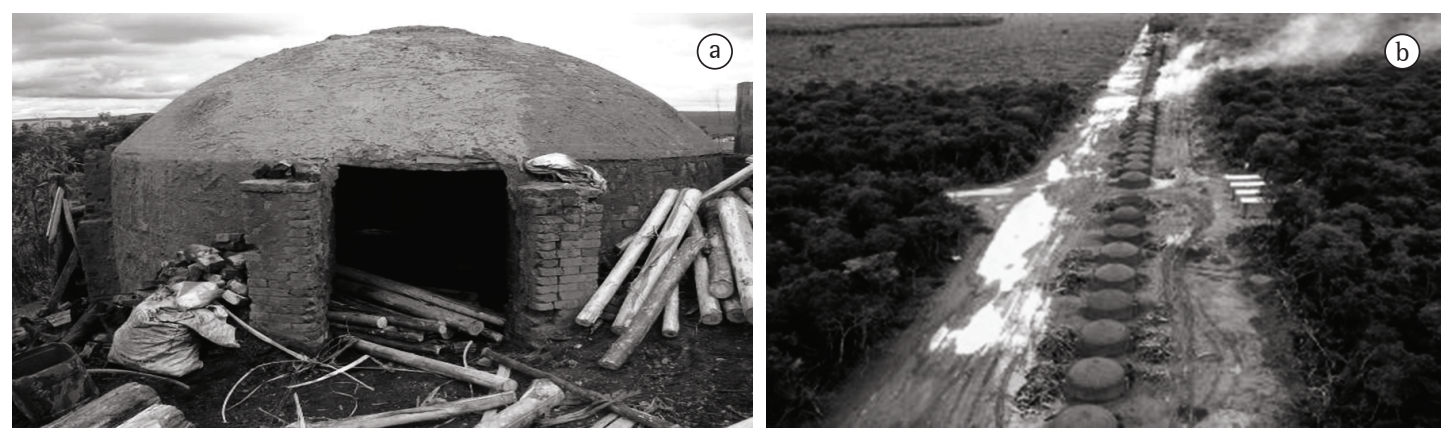

Figura 1. a) Forno “Rabo Quente”; e b) Bateria de fornos “Rabo Quente”. Fonte: Colombo, Pimenta e Hatakeyama (2006). 


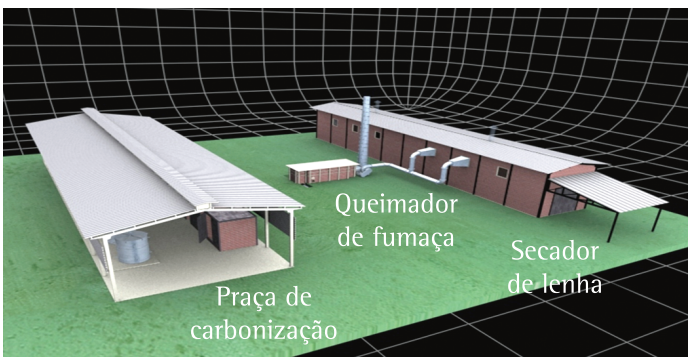

Figura 2. Desenho esquemático da UPC. Fonte: disponibilizado pela Unidade Industrial Pesquisada.

O PCCMV é de concepção simples, constituindo-se em um processo semicontínuo para produção de carvão vegetal. 0 processo de produção consiste basicamente em carregar o cilindro metálico com lenha previamente cortada em tamanho uniforme e com o teor de umidade reduzido. 0 cilindro metálico carregado é fechado na extremidade inferior com uma grelha que permite a circulação do ar e dos fumos decorrentes da carbonização da lenha. Assentado na posição vertical sobre um suporte na base do forno inicia-se a carbonização a partir da ignição da lenha. A fumaça oriunda da carbonização é canalizada para o queimador. Parte do ar quente, proveniente dessa queima, é transferida para a unidade de secagem da lenha que pode contar, opcionalmente, com o auxílio de um sistema de micro-ondas instalado nas paredes externas que emite radiação para a lenha em secagem, facilitando a evaporação. A cada ciclo de carbonização, o cilindro é colocado em resfriamento e então descarregado. Esta concepção constitui o Processo Teórico.

A Unidade de Produção de Carvão Vegetal (UPCV) pesquisada deriva desta concepção teórica e compõe-se das seguintes partes principais: 8 fornos; 3 cilindros metálicos por forno, totalizando 24 cilindros por UPC; 24 grelhas de ferro fundido com chaminé (1 por cilindro); um queimador da fumaça poluente $\mathrm{e}$ produtor de ar quente para a secagem da lenha; uma unidade de secagem da lenha; 1 sistema informatizado para supervisão da carbonização. As partes acessórias são: termopares para controle da temperatura interna dos cilindros; pórtico rolante elétrico equipado com trolleye talha; cavaletes metálicos para carga de lenha e descarga de carvão vegetal; ventilador/exaustor para a sucção da fumaça dos fornos; ventilador/insuflador para conduzir o ar quente para a unidade de secagem da lenha; balança tipo dinamômetro para pesagem da lenha e do carvão vegetal; garfos e pás; gaiolas para medição de volume de carvão vegetal e suporte metálico para grelha. A UPVC da qual se extraíram os dados pesquisados constitui o Processo Pesquisado.
A produção de carvão vegetal pelo Processo Artesanal foi proporcionalmente adaptada de dados coletados numa carvoaria típica, localizada no Paraná (COLOMBO; PIMENTA; HATAKEYAMA, 2006), tornando-se equivalente, em volume, ao Processo Teórico de uma UPCV de 3.500 a $4.000 \mathrm{MDC} / \mathrm{mês}$. A produção pelo Processo Pesquisado, a partir da coleta de dados de 250 carbonizações numa UPCV idealizada para 3.500 a $4.000 \mathrm{MDC} / \mathrm{mês}$ no Estado do Paraná, no período de 05/08 a 03/09, foi comparada inicialmente ao Processo Teórico, conforme consta na Tabela 3.

A análise técnica dos processos (capacidade, produtividade, rendimento, qualidade do produto) foi feita dentro do escopo necessário para a elaboração dos parâmetros econômicos, ambientais, sociais e culturais, sem a pretensão de discutir ou esgotar os aspectos técnicos envolvidos nos processos, ressaltando que todas as informações técnicas foram suportadas pela literatura e pelos dados coletados nas unidades pesquisadas.

A viabilidade econômica dos processos foi atestada por meio do emprego de conceitos e ferramentas amplamente utilizados e consagrados da Engenharia Econômica.

Para a análise comparativa dos processos, quanto ao aspecto ambiental, buscou-se na teoria dados estatísticos para cálculo do balanço de massa, do balanço energético e das quantidades geradas dos diferentes produtos oriundos do processo de carvoejamento, conforme mostrado nas Tabelas 4, 5 e 6 :

Para efeito de cálculos do balanço de massa, utilizaram-se dados constantes da Tabela 4.

Quanto ao balanço energético, a sequência mostrada na Tabela 5 abaixo identifica que a secagem é responsável por $48,7 \%$ da energia total demandada no processo de carbonização.

Complementando, os dois principais produtos oriundos da carbonização (fumaça e carvão) e o poder calorífico destes foram identificados na Tabela 6.

Para analisar o aspecto social dos processos de carbonização, optou-se por montar um cenário do setor carvoeiro no Brasil, no que se refere às relações trabalhistas. Segundo a Organização Internacional do Trabalho (0IT), em 2005 as vítimas do trabalho forçado no mundo eram 12,3 milhões, distribuídos conforme mostrado na Figura 3.

A situação degradante à qual os trabalhadores são submetidos vai além dos alojamentos e cozinhas precários, da ausência de instalações sanitárias, da falta de água potável para beber e da falta de socorro médico. Muitos acidentes deixam sequelas e até 
Tabela 3. Premissas: análise econômica comparativa dos processos: artesanal, teórico e pesquisado.

\begin{tabular}{|c|c|c|c|}
\hline \multicolumn{4}{|c|}{ Hipóteses de base - capacidade 3.500 a $4.000 \mathrm{MDC} / \mathrm{mês}$} \\
\hline & \multicolumn{3}{|c|}{ Tipo de processo } \\
\hline & Artesanal & Teórico & Pesquisado \\
\hline $\begin{array}{l}\text { Capacidade produtiva } \\
\mathrm{MDC} / \mathrm{mês}\end{array}$ & 4.000 & 3.994 & 1.622 \\
\hline $\begin{array}{l}\text { Vida útil considerada em } \\
\text { anos }\end{array}$ & 2,0 & 10,0 & 10,0 \\
\hline \multicolumn{4}{|c|}{ Investimento inicial } \\
\hline Montante em R\$ & 178.500 & 3.000 .000 & 3.000 .000 \\
\hline \multicolumn{4}{|c|}{ Dados técnicos/operacionais } \\
\hline $\begin{array}{l}\text { Número de fornos por } \\
\text { bateria }\end{array}$ & 12 & n.a. & n.a. \\
\hline $\begin{array}{l}\text { Quantidade de baterias no } \\
\text { sistema }\end{array}$ & 9,7 & n.a. & n.a. \\
\hline $\begin{array}{l}\text { Quantidade de fornos no } \\
\text { sistema }\end{array}$ & 117 & 8 & 8 \\
\hline $\begin{array}{l}\text { Quantidade de cilindros } \\
\text { por forno }\end{array}$ & n.a. & 3 & 3 \\
\hline $\begin{array}{l}\text { Capacidade de cada forno } \\
\text { em st de eucalipto }\end{array}$ & 16,00 & n.a. & n.a. \\
\hline $\begin{array}{l}\text { Capacidade de cada } \\
\text { cilindro em st de eucalipto }\end{array}$ & n.a. & 10,4 & 10,4 \\
\hline $\begin{array}{l}\text { Tempo de carbonização } \\
\text { em horas }\end{array}$ & 168 & 10,0 & 16,0 \\
\hline $\begin{array}{l}\text { Produção diária (número de } \\
\text { carbonizações por forno) }\end{array}$ & 0,14 & 2,4 & 1,04 \\
\hline $\begin{array}{l}\text { Razão de conversão } \\
\text { (st de eucalipto/MDC) }\end{array}$ & 2,0 & 1,5 & 1,6 \\
\hline Dias produtivos no mês & 30 & 30 & 30 \\
\hline Número de empregados & 88 & 18 & 18 \\
\hline $\begin{array}{l}\text { Regime de produção em } \\
\text { horas/dia }\end{array}$ & 24 & 24 & 24 \\
\hline $\begin{array}{l}\text { Horas trabalhadas/ } \\
\text { funcionário/mês }\end{array}$ & 180 & 180 & 180 \\
\hline \multicolumn{4}{|c|}{ Custos operacionais } \\
\hline $\begin{array}{l}\text { Impostos s/Vendas } \\
\text { (PIS, COFINS) }\end{array}$ & $9,25 \%$ & $9,25 \%$ & $9,25 \%$ \\
\hline Mão de obra em $\mathrm{R} \$$ /hora & 5,56 & 5,56 & 5,56 \\
\hline $\begin{array}{l}\text { Preço da lenha } R \$ / s t \text { de } \\
\text { eucalipto no pátio }\end{array}$ & 40,00 & 40,00 & 40,00 \\
\hline $\begin{array}{l}\text { Custo médio mensal } \\
\text { histórico da energia } \\
\text { elétrica em } \mathrm{R} \$\end{array}$ & 0,00 & $22.000,00$ & $22.000,00$ \\
\hline $\begin{array}{l}\text { Custo médio mensal } \\
\text { estimado de manutenção/ } \\
\text { bateria (R\$) }\end{array}$ & 600,00 & n.a. & n.a. \\
\hline $\begin{array}{l}\text { Custo médio mensal } \\
\text { estimado de manutenção } \\
\text { (R\$) }\end{array}$ & $5.830,00$ & $6.250,00$ & $6.250,00$ \\
\hline $\begin{array}{l}\text { Depreciação (10\% a.a. } \\
\text { sobre investimento inicial) }\end{array}$ & 0,00 & $300.000,00$ & $300.000,00$ \\
\hline Preço de venda (R\$/MDC) & 115,00 & 115,00 & 115,00 \\
\hline
\end{tabular}

mutilações. Muitas vezes são obrigados a colocar seus filhos no trabalho como forma de aumentar a produção e qualquer desobediência pode lhes custar a própria vida (ORGANIZAÇÃO..., 2005).
Tabela 4. Dados básicos de consumo de carvão e produtividade da lenha.

\begin{tabular}{lc}
\hline \multicolumn{1}{c}{ Descrição } & Unidade \\
\hline 1) Produção carvão vegetal (Brasil) & $9,5-10,5 \mathrm{mi} \mathrm{t} / \mathrm{ano}$ \\
2) Massa de lenha/st eucalipto & $550-580 \mathrm{~kg}$ \\
3) Produtividade média de lenha de & (30\% umidade média) \\
eucalipto & $40-45$ st/ha.ano \\
4) $\eta_{\text {gravimétrico }}$ processo artesanal & (30\% umidade média) \\
(base seca) & n-30\% ou 3,64:1 \\
5) $\eta_{\text {gravimétrico }}$ processo teórico & na média \\
(base seca) & n6-40\% ou 2,63:1 \\
6) $\eta_{\text {volumétrico }}$ processo artesanal & nédia \\
(base seca) & 2 st:1 MDC \\
7) $\eta_{\text {volumétrico }}$ processo teórico & \\
(base seca) & 1,5 st:1 MDC \\
\hline 1) Brasil (2007); 2) e 4) Penedo (1982); 3) Latorre e Cunha (2006); 5) e \\
7) Pimenta (2007); 6) Pinheiro (2006).
\end{tabular}

Muitos são os fatores atribuídos a esta prática, seja em que parte do mundo for: a falta de instrução e de perspectivas de vida dos trabalhadores favorece o trabalho dos aliciadores e a impunidade livra os exploradores (ORGANIZAÇÃO..., 2005).

0 Pacto pela erradicação do trabalho escravo, outra ferramenta importante na luta contra esta prática, articulada pelo Instituto Ethos, em conjunto com a OIT e a ONG Repórter Brasil, firmado em 19 de maio de 2005, tem como signatárias empresas dos mais variados segmentos e prevê o envolvimento dos seus signatários na busca pela regularização das relações de trabalho nas cadeias produtivas constantes da "lista suja" do Ministério do Trabalho e Emprego, a partir do estabelecimento de metas.

Outro documento, especificamente criado para a cadeia produtiva em que a produção do carvão vegetal está inserida, é a "carta-compromisso pelo fim do trabalho escravo na produção do carvão vegetal e pela dignificação, formalização e modernização do trabalho na cadeia produtiva do setor siderúrgico", assinado pela Associação das Siderúrgicas de Carajás - ASICA, pelo Sindicato da indústria do Ferro Gusa do Estado do Maranhão - SIFEMA; Instituto Ethos; Instituto Observatório Social, entre outros (INSTITUTO..., 2004).

Para analisar o aspecto cultural dos processos de carbonização, vê-se que, historicamente, segundo Jacomino et al. (2002), a indústria siderúrgica no Brasil cresceu suportada pelo carvão vegetal. Nos idos do século XVIII, os primeiros fornos de manufatura do ferro-gusa foram desenvolvidos para seu uso.

A industrialização acelerada durante o século XX introduziu o uso do carvão mineral coqueificável para utilização nos altos fornos das indústrias do aço. No 


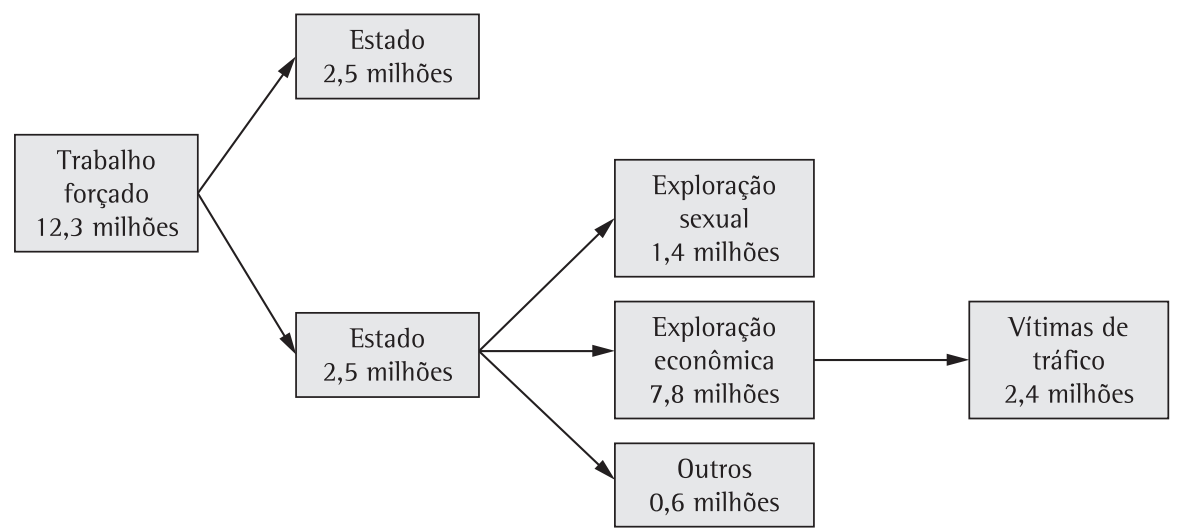

Figura 3. Principais formas de trabalho forçado no mundo. Fonte: Organização Internacional do Trabalho (2005).

Tabela 5. Etapas de Carbonização x Demanda de Energia (madeira 30\% de umidade).

\begin{tabular}{ccccc}
\hline Etapa & $\begin{array}{c}\text { Demanda de energia } \\
\text { p/1 } \mathrm{t} \text { madeira (BS) }\end{array}$ & $\begin{array}{c}\text { Temperatura média } \\
\text { atingida }\left({ }^{\circ} \mathrm{C}\right)\end{array}$ & Produto da fase & $\begin{array}{c}\text { Energia total } \\
\text { demandada }(\%)\end{array}$ \\
\hline 1 (secagem) & $257 \mathrm{Mcal}$ & $100-110$ & Madeira seca & 48,7 \\
11 (torrefação) & $98 \mathrm{Mcal}$ & $250-270$ & Tiço & 18,6 \\
111 (carbonização) & $138 \mathrm{Mcal}$ & $340-350$ & Carvão & 26,1 \\
IV (fixação) & $35 \mathrm{Mcal}$ & $350-360$ & Carvão $75 \% \mathrm{CF}$ & 6,6 \\
Todas & $528 \mathrm{Mcal}$ & $350-360$ & Carvão $75 \% \mathrm{CF}$ & 100,0 \\
\hline
\end{tabular}

Adaptado de Rezende (2006)

Tabela 6. Produtos da carbonização x poder calorífico (madeira $30 \%$ umidade).

\begin{tabular}{|c|c|c|c|}
\hline Carga inicial & \multicolumn{2}{|c|}{ Produto gasoso (fumaça) } & $\begin{array}{l}\text { Produto sólido } \\
\text { (carvão) }\end{array}$ \\
\hline \multirow[t]{2}{*}{$\begin{array}{l}\text { Madeira } \\
1.000 \mathrm{~kg} \\
\text { (base seca) }\end{array}$} & Gás & $\begin{array}{l}\text { Monóxido de carbono } \\
\text { + dióxido de carbono: } \\
160 \mathrm{~kg}\end{array}$ & \multirow{3}{*}{ Carvão 400 kg } \\
\hline & Óleo & $\begin{array}{l}\text { Alcatrão e pirolenhoso } \\
130 \mathrm{~kg}\end{array}$ & \\
\hline $\begin{array}{l}1.300 \mathrm{~kg} \\
\text { (base úmida) }\end{array}$ & Água & $\begin{array}{l}\text { Umidade: } 300 \mathrm{~kg} \\
\text { Água de constituição: } \\
310 \mathrm{~kg}\end{array}$ & \\
\hline Poder calorífico & & $1.295 \mathrm{kcal} / \mathrm{kg}$ & $7.300 \mathrm{kcal} / \mathrm{kg}$ \\
\hline
\end{tabular}

entanto, por razões de custo e da qualidade do ferrogusa produzido a partir do carvão vegetal, evidencia-se que acima de 30\% do ferro-gusa brasileiro, 100\% do ferroliga e 100\% do silício metálico são produzidos a partir de carvão vegetal.

De acordo com as estatísticas do setor siderúrgico, o Brasil é importante fabricante de aço, ferroligas e fundidos de ferro no cenário mundial, ocupando atualmente o segundo lugar na produção de ferroligas e a sétima posição na produção de fundidos de ferro.

A curva de crescimento das indústrias siderúrgicas aponta para um crescimento em todas as áreas abordadas e, culturalmente, a produção de carvão vegetal deve acompanhar esta tendência pelos motivos citados acima.

\section{Resultados e discussão}

\subsection{Comparativo dos resultados quanto ao aspecto técnico}

A análise técnica comparativa entre os processos de carbonização objetivou avaliar tempo de carbonização, consumo de matéria-prima e aproveitamento dos subprodutos. A partir das premissas constantes da Tabela 3, os resultados se referem ao encontrado na carvoaria artesanal do Paraná, Processo Artesanal, adaptada proporcionalmente à capacidade do Processo Teórico, e aos dados encontrados no Processo Pesquisado, conforme Tabela 7.

No período pesquisado, a UPCV operou a 40,6\% da capacidade instalada. Tempo médio de carbonização 68\% acima do esperado, rendimento volumétrico médio 6,7\% menor e rendimento gravimétrico médio 6,8\% menor do que a média esperada. Vale ressaltar que a unidade de secagem de lenha não estava funcionando no regime contínuo e, durante a pesquisa, a umidade da lenha se encontrava acima do previsto para o processo teórico.

\subsection{Comparativo dos resultados quanto ao aspecto econômico-financeiro}

Para efeito de análise comparativa entre os processos consideraram-se os fluxos de caixa. No entanto, não foram considerados: 
- Depreciação no caso do Processo Artesanal: para efeito da operação, os custos alocados em manutenção são suficientes para manter a unidade operacional, além dos dois anos considerados para a vida útil do forno;

- Custo de oportunidade: não se trata unicamente de escolher entre duas alternativas viáveis de investimento, mas de uma segunda alternativa à que se vem praticando e que atenda a outros desígnios, tais como, ser ecologicamente correto, socialmente justo e culturalmente aceito. Por força do amadurecimento da sociedade, a alternativa tende a ser compulsória com o passar do tempo;

- Despesas de comercialização e administrativas: considerados apenas impostos sobre vendas, visto que a apuração das outras despesas pressupõe condição de levantamento exato destes gastos, não sendo possível em uma unidade operacional funcionando em regime de tryout. Além disto, estas mesmas despesas incidiriam similarmente em quaisquer dos processos e, portanto, não teriam influência significativa na avaliação comparativa;

- Capital de giro: da mesma forma que as despesas de comercialização, este custo de difícil apuração durante a pesquisa em qualquer dos processos, incidiria similarmente em quaisquer dos processos, não tendo, portanto, influência significativa na avaliação comparativa.

Dessa forma, as receitas em qualquer um dos fluxos ficam superestimadas, mas nada que possa prejudicar uma análise comparativa, dado que os eventuais acréscimos nas receitas incidem igualmente em quaisquer dos processos.

Tabela 7. Comparativo de resultados de consumo e produção entre processos: artesanal, teórico e pesquisado.

\begin{tabular}{|c|c|c|c|}
\hline \multicolumn{4}{|c|}{$\begin{array}{c}\text { Resultados } \\
\text { Capacidade } 3.500 \text { a } 4.000 \text { MDC/mês }\end{array}$} \\
\hline Tipo de processo & Artesanal & Teórico & Pesquisado \\
\hline $\begin{array}{l}\text { Consumo de lenha em st } \\
\text { de eucalipto/dia }\end{array}$ & 266,67 & 199,68 & 86,53 \\
\hline $\begin{array}{l}\text { Consumo de lenha em st } \\
\text { de eucalipto/mês }\end{array}$ & 8.000 & 5.990 & $2.595,84$ \\
\hline $\begin{array}{l}\text { Capacidade produtiva do } \\
\text { processo em MDC/dia }\end{array}$ & 133,3 & 133,1 & 54,08 \\
\hline $\begin{array}{l}\text { Capacidade produtiva do } \\
\text { processo em MDC/mês }\end{array}$ & 4.000 & 3.993 & $1.622,40$ \\
\hline $\begin{array}{l}\text { Número de carbonizações } \\
\text { no período }\end{array}$ & 500 & 576 & 250 \\
\hline $\begin{array}{l}\text { Tempo de carbonização } \\
\text { total em horas }\end{array}$ & 84.108 & 5.760 & 4.200 \\
\hline $\begin{array}{l}\text { Tempo médio de } \\
\text { carbonização em horas/ } \\
\text { forno }\end{array}$ & 168 & 10 & 16,8 \\
\hline $\begin{array}{l}\text { Rendimento volumétrico } \\
\text { (médio) }\end{array}$ & 2,0 & 1,5 & 1,6 \\
\hline $\begin{array}{l}\text { Rendimento gravimétrico } \\
\text { (médio) }\end{array}$ & $25-30 \%$ & $36-40 \%$ & $35,4 \%$ \\
\hline
\end{tabular}

A análise dos processos de carbonização objetivou avaliar primeiramente a viabilidade econômica comparada entre o Artesanal e o Teórico, a partir das premissas constantes da Tabela 3. Buscou-se, também, comparativamente ao Processo Teórico, mostrar os resultados alcançados no Processo Pesquisado, conforme verificado nas instalações ainda em fase de tryout, que obtiveram os resultados mostrados na Tabela 8.

A partir dos dados constantes da Tabela 8, calcularam-se os indicadores econômico-financeiros dos processos Artesanal, Teórico e Pesquisado, apresentados para comparação, na Tabela 9.

\section{Comparativo dos resultados quanto ao aspecto ambiental}

\subsection{Balanço teórico de massa}

Da Tabela 4, estimaram-se as quantidades de madeira necessárias para cada processo a partir do consumo médio anual de carvão vegetal e considerando-se o uso da lenha de eucalipto para a produção do carvão. Os resultados são mostrados na Tabela 10.

Tabela 8. Comparativo dos resultados financeiros anuais dos processos: artesanal, teórico e pesquisado.

\begin{tabular}{|c|c|c|c|}
\hline \multicolumn{4}{|c|}{$\begin{array}{l}\text { Resultados financeiros anuais }(\mathrm{R} \$ 1.000,00) \text { - capacidade } \\
3.500 \text { a } 4.000 \mathrm{MDC} / \mathrm{Mês}\end{array}$} \\
\hline & Artesanal & Teórico & Pesquisado \\
\hline Faturamento previsto & 5.520 & 5.511 & 2.239 \\
\hline $\begin{array}{l}\text { Custo total de produção c/ } \\
\text { impostos }\end{array}$ & 5.477 & 4.240 & 2.308 \\
\hline Custo da lenha & 3.840 & 2.875 & 1.246 \\
\hline Custo da mão de obra & 1.057 & 216 & 216 \\
\hline Custo da energia elétrica & 0 & 264 & 264 \\
\hline Custo estimado da manutenção & 70 & 75 & 75 \\
\hline Custo da depreciação & - & 300 & 300 \\
\hline Impostos s/Vendas (PIS, COFINS) & 511 & 510 & 207 \\
\hline $\begin{array}{l}\text { Custo unitário de produção } \\
\text { (R\$/MDC) }\end{array}$ & 114,11 & 88,48 & 118,56 \\
\hline
\end{tabular}

Tabela 9. Indicadores econômico-financeiros: comparativo entre processos.

\begin{tabular}{lccc}
\hline \multicolumn{4}{c}{$\begin{array}{c}\text { Indicadores econômico-financeiros: } \\
\text { comparativo entre processos }\end{array}$} \\
\hline Indicadores/tipo de processo & Artesanal & Teórico & Pesquisado \\
\hline Lucratividade estimada (\%) & $0,8 \%$ & $25,4 \%$ & $-3,4 \%$ \\
Rentabilidade simples (\%) & $23,8 \%$ & $42,4 \%$ & $-2,3 \%$ \\
Payback simples (anos) & 4,2 & 2,36 & Inexistente \\
Payback descontado (anos) & 6,4 & 2,95 & Inexistente \\
VPL (Valor Presente Líquido & 62 & 3.733 & -3.028 \\
TMA 12\%) & & & Inexistente \\
Taxa interna de retorno (\%) & $20 \%$ & $41 \%$ & \\
\hline
\end{tabular}


Ainda da Tabela 4 (2) e (3), depreende-se a produtividade média de florestas de silvicultura de eucalipto, evidenciada na Tabela 11.

Da relação entre as Tabelas 10 e 11, evidencia-se a necessidade de áreas florestais de silvicultura de eucalipto, conforme Tabela 12.

Os resultados evidenciam que o Processo Teórico, a partir de lenha de eucalipto, mostra uma economia potencial anual de cerca de $\mathbf{5 5 0 . 0 0 0}$ ha de florestas, interessante do ponto de vista ambiental.

Por outro lado, do balanço de massas, comparando teoricamente os dois processos de carbonização realizados com lenha de eucalipto, no que se refere à emissão de fumos durante o processo a partir de dados derivados da Tabela 10 e Tabela 6 , as diferenças estão evidenciadas na Tabela 13.

Os 9,1 milhões $t$ de diferença na emissão anual de fumos, tomando-se ainda em consideração que a queima da fumaça transforma a parte mais poluente dos fumos em gases limpos, representam uma considerável melhoria potencial do ponto de vista ambiental.

\subsection{Balanço energético teórico}

A Tabela 5 mostra que a secagem de uma madeira de eucalipto com 30\% de umidade é responsável por $48,7 \%$ da energia total demandada no processo de carbonização.

A Tabela 6 mostra que se obtêm dois produtos principais oriundos do processo de carbonização - fumaça e carvão - com poderes caloríficos de 1.295 e $7.300 \mathrm{kcal} / \mathrm{kg}$, respectivamente.

A partir das informações constantes das Tabelas 5 e 6, evidencia-se a energia contida na fumaça gerada na carbonização de $1.300 \mathrm{~kg}$ de madeira (1.000 kg base seca), conforme mostrado na Tabela 14 , sendo que PCF $=$ poder calorífico da fumaça.

Para aquecer até $100{ }^{\circ} \mathrm{C}$ e evaporar $1 \mathrm{~kg}$ de água, são necessárias em torno de $600 \mathrm{kcal}$. Adicionalmente, de acordo com a Tabela 5, a energia necessária para evaporação da água de constituição de $1 \mathrm{t}$ de madeira base seca é de 257 Mcal. Dessa forma, a energia total envolvida no processo de evaporação da água contida em $1.300 \mathrm{~kg}$ de madeira base úmida (30\% de umidade) é de $437 \mathrm{Mcal}$, conforme evidenciado na Tabela 15.

A energia contida em $900 \mathrm{~kg}$ de fumaça, de acordo com a Tabela 14 se mostra acima do necessário para evaporar totalmente a água contida na madeira, conforme Tabela 15. Isto equivale dizer que o diferencial positivo do Processo Teórico em relação ao Processo Artesanal está no aproveitamento do poder energético da fumaça em função de:

- Aumento do rendimento da carbonização, obtendo maior quantidade de carvão em relação ao processo artesanal (suporte para a viabilidade econômica);

- Redução da quantidade do principal insumo do processo (lenha) para obtenção do carvão (suporte para a viabilidade econômica);

- Redução do abate de florestas nativas (suporte para a viabilidade ambiental);

- Redução e modificação da emissão dos gases, obtendo gases mais limpos e em menor volume (suporte para a viabilidade ambiental);

- Alcançados (a) e (b) tornar possível a operação dentro dos padrões trabalhistas exigidos por lei (suporte para a viabilidade social).

Considerando os dados constantes do Balanço Teórico de Massa, do Balanço Energético Teórico e Tabela 7 - Comparativo dos Resultados quanto ao Aspecto Técnico, destacam-se:

- $0 \eta_{\text {volumétrico }}$ do Processo Pesquisado atingiu 1,6, significando uma economia de 517.000 ha/ano de florestas plantadas de eucalipto quando comparado com o Processo Artesanal. $0 \eta_{\text {volumétrico }}$ de 1,5 previsto

Tabela 11. Produtividade de floresta de silvicultura de eucalipto.

\begin{tabular}{cc}
\hline $\begin{array}{c}\text { Massa média de madeira/ } \\
\text { st de eucalipto }(\mathrm{t})\end{array}$ & $\begin{array}{c}\text { Produtividade média da madeira } \\
\text { (t/ha.ano - 30\% de umidade) }\end{array}$ \\
\hline (2) 0,565 & $22-26$ \\
\hline
\end{tabular}

Tabela 12. Necessidade anual de florestas de eucalipto para produção de carvão vegetal.

\begin{tabular}{ccc}
$\begin{array}{c}\text { Produtividade média } \\
\text { da floresta plantada } \\
\text { (t/ha) }\end{array}$ & $\begin{array}{c}\text { Área necessária de } \\
\text { floresta plantada } \\
\text { (processo artesanal) } \\
\text { (ha) }\end{array}$ & $\begin{array}{c}\text { Área necessária de } \\
\text { floresta plantada } \\
\text { (processo teórico) } \\
\text { (ha) }\end{array}$ \\
\hline 24 & 1.971 .000 & 1.425 .000 \\
\hline
\end{tabular}

Tabela 10. Necessidade anual de madeira (BS base seca e BU base úmida 30\% de umidade média) para produção de carvão vegetal.

\begin{tabular}{cccccccc}
\hline $\begin{array}{c}\text { Produção média } \\
\text { anual de carvão } \\
\text { vegetal (Mt) }\end{array}$ & $\begin{array}{c}\text { Relação gravimétrica } \\
\text { madeira/carvão processo } \\
\text { artesanal }\end{array}$ & $\begin{array}{c}\text { Relação gravimétrica } \\
\text { madeira/carvão processo } \\
\text { teórico }\end{array}$ & $\begin{array}{c}\text { Consumo médio anual de } \\
\text { madeira processo artesanal } \\
\text { (Mt) }\end{array}$ & $\begin{array}{c}\text { Consumo médio anual de } \\
\text { madeira processo teórico } \\
\text { (Mt) }\end{array}$ \\
\hline (1) 10 & BS & BU & BS & BU & BS & BU & BS \\
& (4) 3,64 & 4,73 & (5) 2,63 & 3,42 & 36,4 & 47,3 & 26,3 \\
\hline
\end{tabular}



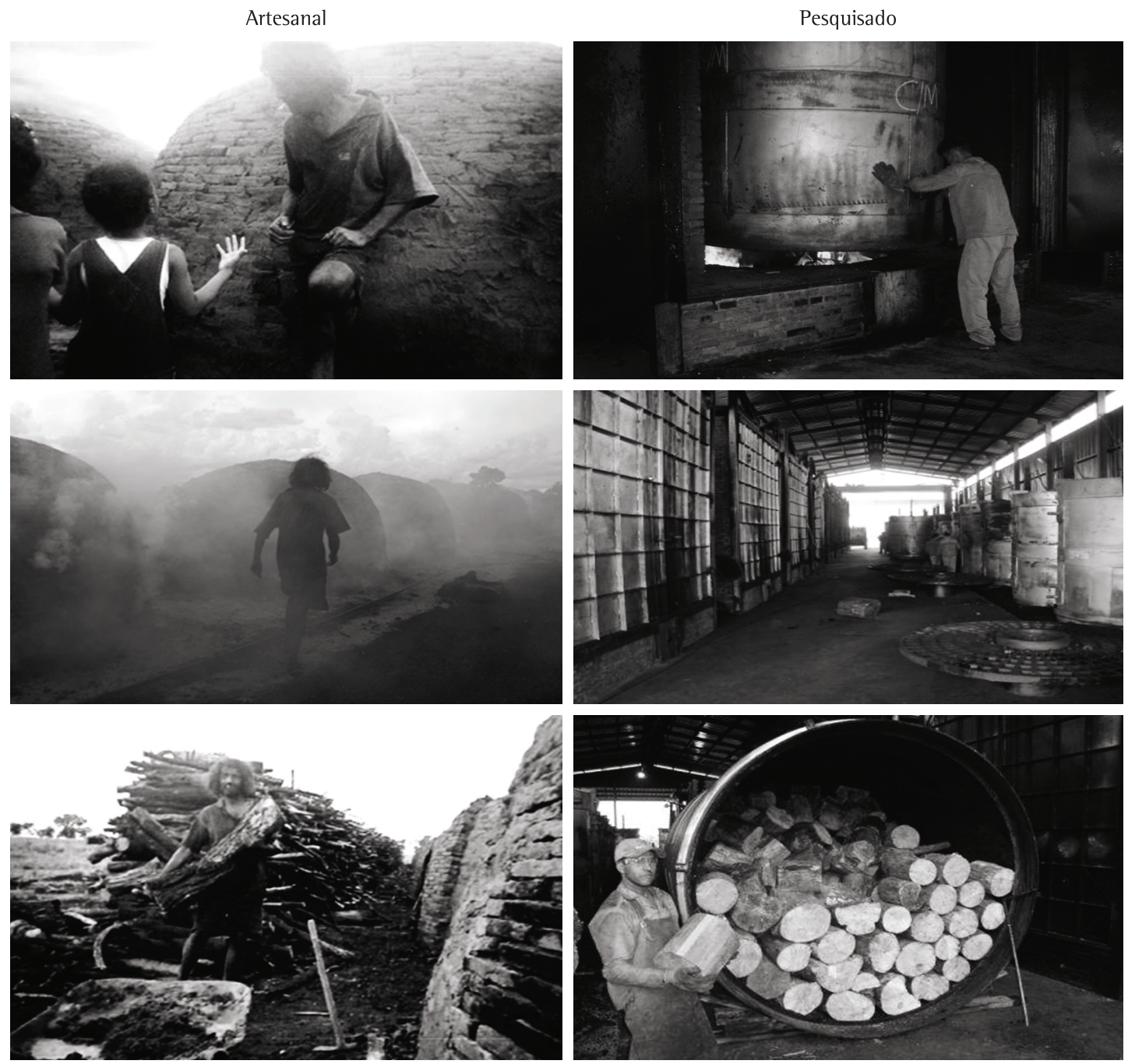

Fonte: Girassolidário (2004)

Fonte: disponibilizadas pela unidade pesquisada (2007)

Figura 4. Fotos comparativas entre os processos: artesanal e pesquisado.

Tabela 13. Comparativo da emissão de fumos entre dois processos de carbonização.

\begin{tabular}{cccccccc}
\hline \multicolumn{2}{c}{ Artesanal 25\% a $30 \%$ de rendimento gravimétrico } & & & \multicolumn{3}{c}{ Teórico 36\% a $40 \%$ de rendimento gravimétrico } \\
\cline { 1 - 3 } $\begin{array}{c}\text { Consumo médio anual de } \\
\text { madeira (Mt) }\end{array}$ & $\begin{array}{c}\text { Emissão anual de fumos } \\
\text { (Mt) }\end{array}$ & $\begin{array}{c}\text { Tipo de } \\
\text { fumos }\end{array}$ & & $\begin{array}{c}\text { Consumo médio anual de } \\
\text { madeira (Mt) }\end{array}$ & $\begin{array}{c}\text { Emissão anual de fumos } \\
\text { (Mt) }\end{array}$ & $\begin{array}{c}\text { Tipo de } \\
\text { fumos }\end{array}$ \\
\hline 47,3 & 32,7 & Poluente & 34,2 & 23,6 & Limpo \\
\hline
\end{tabular}

Tabela 14. Energia contida na fumaça para $1 \mathrm{t}$ de madeira (base seca).

\begin{tabular}{ccc}
\hline PCF (kcal/kg) & Fumaça $(\mathrm{kg})$ & Energia contida na fumaça (Mcal) \\
\hline 1.295 & 900 & $1.165,5$ \\
\hline
\end{tabular}

no Processo Teórico apontava para uma possibilidade de economia da ordem de 550.000 ha/ano;

- 0 mesmo $\eta_{\text {volumétrico }}$ de 1,6 significa uma redução, quando comparado com o Processo Artesanal, de cerca de 8.550.000 t/ano na emissão de fumos provenientes da carbonização de madeira de eucalipto plantado. $0 \eta_{\text {volumétrico }}$ de 1,5 previsto no Processo Teórico apontava para uma possibilidade de redução na emissão de fumos da ordem de 9.100 .000 t/ano;

- A transformação dos fumos poluentes em gases limpos se verificou, uma vez que o queimador de fumaça se encontrava em funcionamento durante o período pesquisado;

- A secagem da lenha, no nível esperado, não se verificou, pois a unidade de secagem da lenha estava operando descontinuamente em regime de tryout durante o período pesquisado. 
Tabela 15. Energia para secagem de $1.300 \mathrm{~kg}$ de madeira.

\begin{tabular}{ccccc}
\hline $\begin{array}{c}\text { Energia para evaporação } \\
\text { de } \mathbf{1 ~ k g ~ d e ~ a ́ g u a ~ ( k c a l ) ~}\end{array}$ & $\begin{array}{c}\text { Umidade contida em } \\
\mathbf{1 . 3 0 0} \mathrm{kg} \text { de madeira }(\mathrm{kg})\end{array}$ & $\begin{array}{c}\text { Energia para evaporação } \\
\text { da umidade (Mcal) }\end{array}$ & $\begin{array}{c}\text { Energia para evaporação da } \\
\text { água de constituição (Mcal) }\end{array}$ & $\begin{array}{c}\text { Energia para evaporação } \\
\text { da água total (Mcal) }\end{array}$ \\
\hline 600 & 300 & 180 & 257 & 437 \\
\hline
\end{tabular}

\subsection{Comparativo dos resultados quanto ao aspecto social}

Considerando o cenário montado para análise do aspecto social e as características do processo industrial de produção de carvão vegetal pelo PCCMV, observam-se as diferenças quanto:

- Ao cumprimento às leis trabalhistas vigentes no Brasil;

- À remuneração praticada e os benefícios assistenciais praticados pela indústria;

- Às condições ambientais no local de trabalho;

- À possibilidade de inclusão social da força de trabalho.

A comparação quanto ao aspecto social entre os processos de carbonização Artesanal e Pesquisado comprovam a diferença de perfil nestes dois processos, conforme mostrada na sequência de fotos retratadas por crianças na faixa etária entre 7 e 9 anos, entre elas, Ana Paula de Oliveira, Bruno de Castro e Elizeu de Oliveira Silva, filhos desses trabalhadores, num projeto denominado "Luz das Carvoarias", desenvolvido pela organização não governamental Girassolidário (2007), com o apoio do Fundo de Investimentos Culturais de Mato Grosso do Sul e da Vivo S/A e faz parte do programa Direito de Crescer, também coordenado pela ONG, no lado esquerdo da Figura 4.

\subsection{Comparativo dos resultados quanto ao aspecto cultural}

Considerando o cenário montado para análise do aspecto social e as características do processo industrial de produção de carvão vegetal pelo PCCMV e o comparativo dos resultados econômicos, destacam-se:

- 0 suporte da viabilidade econômica do Processo Teórico quando comparado com o processo artesanal mostra-se promissor e isto é importante propulsor das mudanças culturais, principalmente em se tratando de sistemas operacionais da economia basal;

- As pressões que a sociedade em amadurecimento vem exercendo no sentido de promover a inclusão social da parcela mais carente da população e a procura de atividades mais limpas e ambientalmente corretas têm respaldo dentro do Processo Teórico.

\section{Conclusões}

Quanto aos aspectos técnicos, o Processo Pesquisado está tecnologicamente embasado, aborda aspectos fundamentais da possibilidade de construir unidades operacionalmente adequadas que possam atingir as metas propostas de se obter um processo suficientemente eficaz e capaz de atender aos desígnios de operar de forma limpa, dentro dos padrões da legislação trabalhista e de contribuir para a inclusão social da força de trabalho e suas famílias. A UPCV foi construída adequadamente e está operando em regime de tryout, para efeito de correção de detalhes de projeto e treinamento da força de trabalho da unidade, uma vez que a esta cabe o papel de showroom para empresas interessadas no processo;

Quanto aos aspectos econômicos, o processo teórico mostrou, por meio da análise dos indicadores adotados, a viabilidade econômica buscada. 0 sucesso prático buscado nas operações de tryout do Processo Pesquisado, para atingir os parâmetros técnicos de produtividade, rendimentos volumétrico e gravimétrico, almejados por ocasião do desenvolvimento do processo teórico, é de fundamental importância para a consecução do proposto quando do início do projeto por parte da empresa, ou seja, um processo sustentável de produção de carvão vegetal quanto aos aspectos ecológico, econômico, social e cultural. Segundo parecer dos responsáveis pelo projeto, três aspectos básicos devem ser cumpridos na sequência dos testes, a saber:

- A UPCV deve funcionar no regime contínuo para que os sistemas de queima da fumaça e de secagem da lenha tenham a oportunidade de cumprir suas tarefas a contento depois de atingir o equilíbrio térmico;

- A lenha deverá atingir a umidade prevista no projeto teórico e, portanto, contribuir positivamente para o alcance dos parâmetros técnicos previstos;

Que não ocorram interrupções da operação para que não se comprometa a eficiência e a produtividade, devido às variações no gradiente de temperatura do processo.

Alguns desvios, presenciados durante a pesquisa, foram por questões de habilidades operacionais devidos a pouca familiaridade dos operadores com a própria operação e àqueles relacionados a pequenos problemas técnicos, considerados normais durante o tryout, que contribuíram para a baixa produtividade encontrada. 
Concluídas estas correções, o Processo Pesquisado deverá alcançar a produtividade em MDC/dia e em rendimentos gravimétrico e volumétrico, necessários e suficientes para atingir a viabilidade econômica.

Quanto aos aspectos ambientais, a possibilidade de se alcançar as melhorias propostas por ocasião da construção do Processo Teórico, de diminuir a necessidade de madeira e, portanto, diminuir a necessidade de abate de florestas nativas, assim como a possibilidade de se usar somente florestas plantadas, diminuindo ao mesmo tempo a emissão de fumos e mudando a natureza deles de poluentes para limpos, foi conseguida durante a operação tryout da UPCV. A melhoria esperada para quando a unidade de secagem da lenha estiver operando na sua plenitude e o restante da unidade estiver operando no regime contínuo pode alcançar ou mesmo suplantar as expectativas do Processo Teórico, segundo parecer dos técnicos da UPCV;

Quanto aos aspectos sociais, a força de trabalho na UPCV pesquisada estava, por ocasião da pesquisa, remunerada de acordo com a legislação trabalhista vigente; usava equipamentos de proteção individual adequados às tarefas executadas; contava com restaurante asseado e refeições supervisionadas por nutricionista e dispunha de plano de assistência médica;

Quanto aos aspectos culturais, a proposição de se construir e implantar uma alternativa que contribua para a sustentabilidade do processo de produção de carvão vegetal está intimamente ligada à tradição da indústria siderúrgica brasileira, portanto, a iniciativa tem o suporte cultural necessário e suficiente.

Cabe considerar, a par das conclusões, que:

- A atual conjuntura nacional de crescimento e necessidade de se aumentar a taxa deste, a melhoria da distribuição da renda, a adoção de tecnologias mais limpas e a promoção da inclusão social, apontam a premência de iniciativas como esta. Ao mesmo tempo, apontam para a necessidade absoluta de apoiá-las, por meio de políticas eficazes, com a aplicação de medidas de repressão ao abate indiscriminado de florestas nativas, que dão ensejo a atividades escusas de carvoejamento, correspondentes a cerca de 50\% da produção brasileira, não contribuindo com os impostos devidos e nem remunerando adequadamente a força de trabalho;

- Embora não sendo parte do escopo do trabalho a análise financeira ou o equacionamento das fontes de recursos, este é outro campo no qual uma política séria de suporte às iniciativas privadas dedicadas à sustentabilidade deveria ser erguida, no intuito de garantir operacionalmente para a futura sociedade brasileira, a preservação das riquezas de base.

\section{Referências}

ALMEIDA, F. Os desafios da sustentabilidade. Rio de Janeiro: Elsevier, 2007.

ASSOCIAÇÃO BRASILEIRA DE PRODUTORES DE FLORESTAS PLANTADAS. Anuário estatístico da ABRAF: ano base 2006. Brasília, 2007. Disponível em: http://www. abraflor.org.br/estatisticas/anuario-ABRAF-2007.pdf. Acesso em: 15 jul 2007.

BRASIL. Ministério da Agricultura, Pecuária e Abastecimento; Ministério da Ciência e Tecnologia, Ministério de Minas e Energia e Ministério do Desenvolvimento, Indústria e Comércio Exterior. Diretrizes de política de agroenergia 2006-2011. Brasília, 2005.

BRASIL. Ministério de Minas e Energia. Balanço Energético Nacional BEN 2007 - Base 2006, Preliminar. Brasília, 2007. Disponível em: <http://www.mme.gov. br>. Acesso em: 15 out. 2007.

colombo, S. F. 0.; PIMENTA, A. S.; HATAKEYAMA, K. Produção de carvão vegetal em fornos cilíndricos verticais: um modelo sustentável. In: SIMPÓSIO DE ENGENHARIA DE PRODUÇÃO - SIMPEP, 13., 2006, Bauru. Anais... Bauru: Universidade Estadual Paulista, 2006.

FERREIRA, O. C. 0 futuro do carvão vegetal na siderurgia: emissão de gases de efeito estufa na produção e consumo do carvão vegetal. Revista Economia \& Energia, ano 4, n. 21, 2000.

GIRASSOLIDÁRIO. Projeto Luz nas carvoarias executado em 2004. Disponível em: <http://www.girassolidario.org. br/projetosociais/executados>. Acesso em: 05 out. 2007.

GOMES, P. A.; OLIVEIRA, J. B. Teoria da carbonização da madeira. In: PENEDO, W. R. (Comp.). Uso da madeira para fins energéticos. Belo Horizonte: CETEC, 1980. 158 p. (Série Publicações Técnicas, n. 1).

GUARDABASSI, P. M. Sustentabilidade da biomassa como fonte de energia: perspectivas para países em desenvolvimento. 2006. 132 f. Dissertação (Mestrado em Energia)-Universidade São Paulo, São Paulo, 2006.

INSTITUTO CARVÃO CIDADÃO. Carta compromisso. Disponivel em: http://www.carvaocidadao.org.br/carta. asp. Acesso em: 15 out. 2007.

JACOMINO, V. M. F. et al. Controle ambiental das indústrias de produção de ferro-gusa em altos-fornos a carvão vegetal. Belo Horizonte: Projeto Minas Ambiente, 2002.

JUVILLAR, J. B. Tecnologias da transformação da madeira em carvão vegetal. In: PENEDO, W. R. (Comp.). Uso da madeira para fins energéticos. Belo Horizonte: CETEC, 1980. 158 p. (Série Publicações Técnicas, n. 1).

LATORRE, F. L., CUNHA, W. L. P. Evolução da produção e utilização de energia renovável na Acesita Energética. In: SEMINÁRIO: Prática, Logística, Gerenciamento e Estratégias para o Sucesso da Conversão da Matéria Lenhosa em Carvão Vegetal para Uso na Metalurgia e Indústria, 2006, Belo Horizonte. Anais... Belo Horizonte, 2006.

LÚC10, Á. DPC: uma tecnologia inovadora e altamente competitiva em constante evolução. In: SEMINÁRIO: Prática, Logística, Gerenciamento e Estratégias para o Sucesso da Conversão da Matéria Lenhosa em Carvão Vegetal para Uso na Metalurgia e Indústria, 2006, Belo Horizonte. Anais... Belo Horizonte, 2006.

ORGANIZAÇÃO INTERNACIONAL DO TRABALHO - OIT. Trabalho escravo no Brasil e no mundo. Relatório Global 2005. Disponível em: <http://www.oitbrasil.org. br>. Acesso em: 15 out. 2007. 
OLIVEIRA, J. B. et al. Produção de carvão vegetal - aspectos técnicos. ln: PENEDO, W. R. (Comp.). Produção e utilização de carvão vegetal. Belo Horizonte: CETEC, 1980. 393 p. (Série Publicações Técnicas, n. 8).

PENEDO, W. R. (Comp.). Produção e utilização de carvão vegetal. Belo Horizonte: CETEC, 1980. 393 p. (Série Publicações Técnicas, n. 8).

PINHEIRO, P. C. C. et al. A produção de carvão vegetal: teoria e prática. Belo Horizonte, 2006.
REZENDE, M. E. Produção de carvão vegetal - importância do conhecimento fundamental. Belo Horizonte, 2006. Curso: Fundamentos e práticas da carbonização da biomassa, ministrado durante o Seminário: Prática, logística, gerenciamento e estratégias para o sucesso da conversão da matéria lenhosa em carvão vegetal para uso na metalurgia e indústria.

SAMPAIO, R. S. Produção de metais com biomassa plantada. In: MELLO, M. G. (Org.). Biomassa: energia dos trópicos em Minas Gerais. Belo Horizonte: LabMídia. 2001, p. 164.

\title{
Sustainable charcoal production process focusing the environmental, economical, social and cultural aspects
}

\begin{abstract}
Brazil accounts for approximately one third of the world's charcoal production, and around ninety percent of that is destined to the Brazilian production of pig-iron, alloys iron, pure silicon, among others. Almost 75\% of the charcoal is still produced through the traditional handcraft method, and almost half of firewood still derives from native forests. The pressure for ecologically-right, socially fair and economically feasible production has driven the search for cleaner and more efficient technologies. Researching a metallic vertical cylinder at an industrial charcoal production unit and a traditional handcraft unit, both located on the State of Parana, this paper intends to show that the industrial production process can replace the traditional one. According to the sustainability pillars, this industrial process may enable the saving of $25 \%$ of firewood, pointing to economical feasibility and an ecologically-right and socially fair process under the Brazilian labor legislation.
\end{abstract}

\section{Keywords}

Charcoal production. Charcoal. Renewable energy. 